


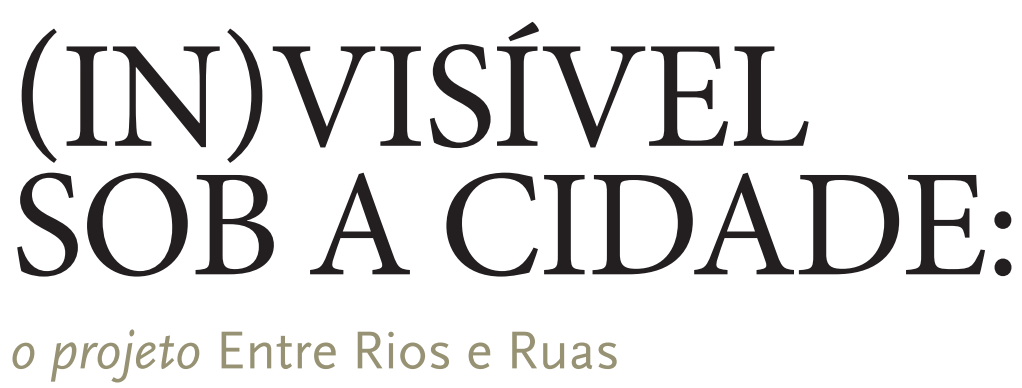

ISABELA PRADO*

RESU MO O projeto Entre Rios e Ruas procura refletir acerca das relações entre cidade, meio ambiente e indivíduo, tendo como ponto de partida a relação que Belo Horizonte estabeleceu desde sua fundação e estabelece ainda hoje com os rios e córregos presentes em seu território. Composto por desenhos, fotografias, objetos, vídeos, instalações e performances, Entre Rios e Ruas quer tornar novamente visíveis os rios que correm sob a cidade e, ao explicitar o traçado desses córregos na malha urbana, repensar nossa relação com o que está a nossa volta. A ocupação do espaço urbano e sua relação com o meio ambiente é uma questão que perpassa todos os trabalhos. Busca-se, por meio da metáfora, da participação do espectador e da experiência espacial, uma proposta de recriação da cidade, ativada pela arte e sua força de invenção.

PALAVRAS-CHAVE Arte contemporânea. Meio ambiente. Rios urbanos.

\section{(IN)VISIBLE UNDER THE CITY:}

\section{The project Entre Rios e Ruas}

ABSTRACT The project Entre Rios e Ruas aims at pondering upon the relations between city, environment, and individual, the starting point being the relation that Belo Horizonte has established with rivers and streams in its territory since its foundation. Composed of drawings, photographs, videos, installations, objects and performances, Entre Rios e Ruas sheds new light on the perception of rivers flowing underneath the city and, by pointing out their paths within the urban grid, the work rethinks our relationship with the surroundings. The occupation of urban space and its relation with the environment is a recurrent issue. With the use of metaphor, by enhancing the participation of the viewer, and by means of a spatial experience, the project proposes a re-creation of the city, activated by art and its inventiveness.

KEYWORDS Contemporary art. Environment. Urban rivers.

*Artista plástica e Mestre em artes visuais pela Indiana University (Estados Unidos da América).

E-mail: <pradoisabela@hotmail.com>. 


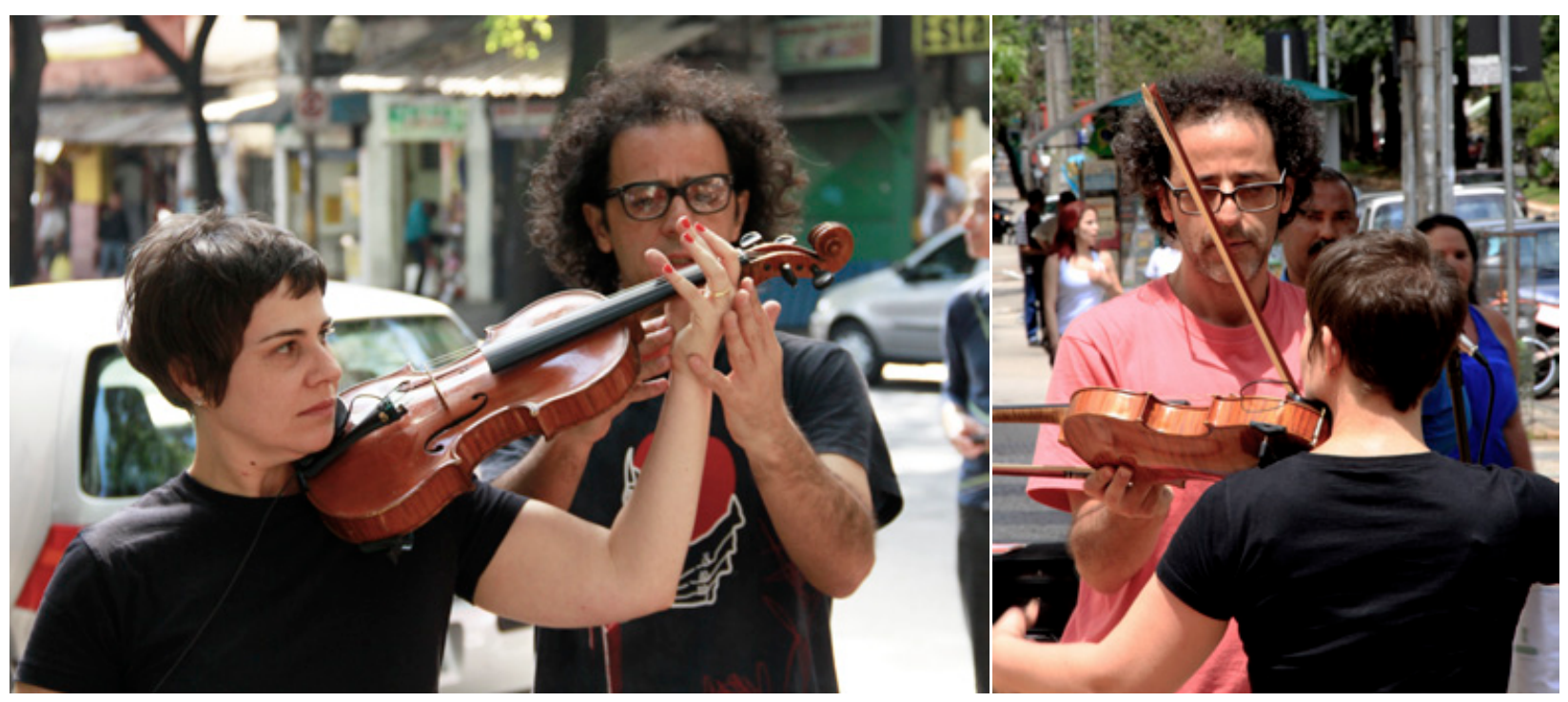

ISABELA PRADO/FOTO: FERNANDO ANCIL

Lição: nessa rua tem um rio, performance, 60 min, 2011-2012.

Participação especial: Paulo Thomas

m 2006, volto a Belo Horizonte após cinco anos de ausência. Em meio ao
estranhamento já previsível em situações desse tipo, deparo-me com uma alteração importante na paisagem local, quando parte do Ribeirão Arrudas, um rio muito presente na história, na memória, na paisagem da cidade, deixa de existir ao ser encoberto por uma avenida.

O rio se apaga da paisagem, em nome da chamada Linha Verde - Boulevard Arrudas. Havia propagandas na mídia local, nas traseiras dos ônibus, vendendo uma cidade feliz que enterrava seu rio. Achei que ali havia um ponto para reflexão. De repente, o rio desapareceu da paisagem - embora de fato continuasse lá, como poeira embaixo do tapete.

Em contraste a tudo isso, uma ex-colega do mestrado, coreana, também estava voltando para seu país, para Seul, e comentava com alegria o fato de encontrar o Rio Chongyechong descoberto e revitalizado - uma experiência oposta à minha. Situações contrastantes no retorno a casa, o que me causou a sensação de que estávamos andando para trás.

De volta a Belo Horizonte, passo a morar em um apartamento e a conviver com o aparecimento de mofo nas paredes. O apartamento era térreo e a umidade vinha 


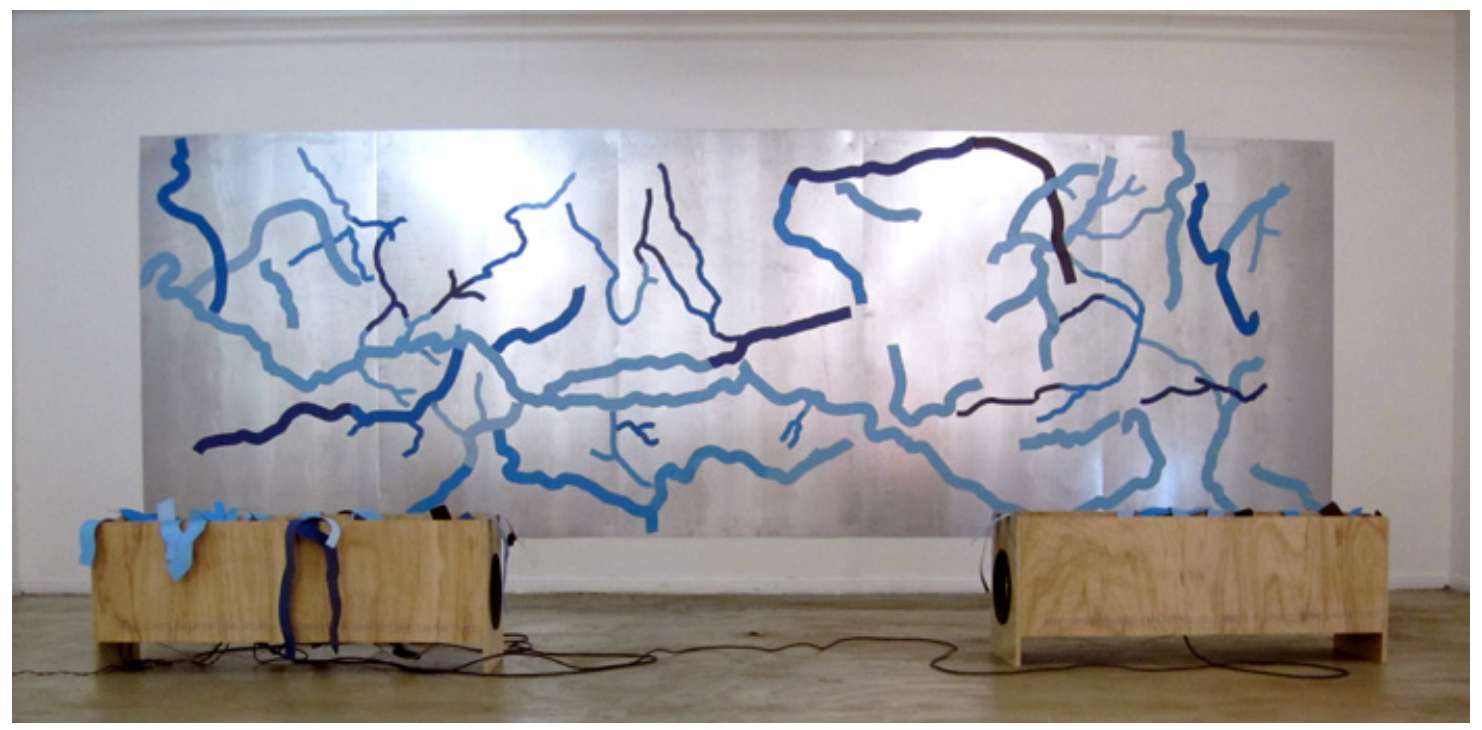

ISABELA PRADO/ FOTO: GUILHERME MACHADO Repaisagem, Instalação, 2010.

do chão, dado que o apartamento se localizava sobre um dos córregos canalizados da cidade, o Córrego da Serra. O rio invadia minha vida, minha casa.

A partir dessas percepções, ganhou corpo a necessidade de discutir o tema por meio de uma produção visual, plástica. E meu trabalho passou a não mais se dissociar do interesse por esse tema. Uma produção que busca trazer à luz a questão, ao tornar visíveis rios e córregos que vêm sendo há muito tempo encobertos na cidade. E daí veio um nome: Entre Rios e Ruas.

O conjunto de trabalhos que compõem o projeto Entre Rios e Ruas toma como ponto de partida a relação que Belo Horizonte estabeleceu desde sua fundação e estabelece ainda hoje com os rios e córregos presentes em seu território. Como se sabe, as especificidades das bacias hidrográficas da região não foram consideradas no planejamento da cidade, particularmente no espaço urbano circunscrito pela Avenida do Contorno, sendo

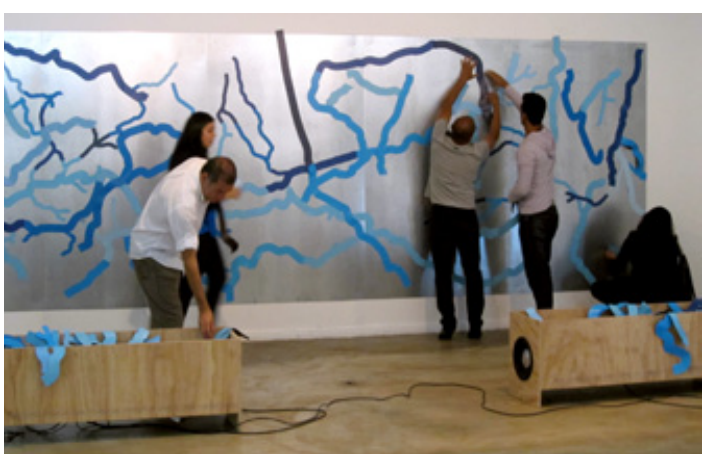

ISABELA PRADO/ FOTO: GUILHERME MACHADO Repaisagem, Instalação, 2010. 
assim condicionadas ao traçado geométrico e ortogonal das ruas belorizontinas, estruturadoras de uma malha viária quadriculada na área central.

Iniciado em 2006 - e composto por desenhos, fotografias, objetos, vídeos, instalações e performances -, Entre Rios e Ruas procura refletir acerca das relações entre cidade, meio ambiente e indivíduo. O passo inicial foi meu testemunho cotidiano do rio invadindo meu apartamento na forma de mofo, desafiando todas as tentativas de contê-lo e de restringir sua trajetória. E o mofo foi formando mapas dentro da minha casa. Desde 2007, comecei a documentar esses mapas, que, fluidos, iam se modificando com o tempo.

Surge, então, a série de imagens que dá origem ao vídeo Mapa Mofo (2007-2012), nas quais o desenho úmido que vai se insinuando diariamente é enquadrado, formando espécies de manchas cartográficas. Lentamente, no vídeo projetado sobre cantos de espaços internos, os mapas formados pelo bolor conduzem uns aos outros, paulatinamente alterando e expandindo, fronteiras. O branco ganha tons ocres, o plano adquire volume: o rio se insinua por entre tijolos e massa corrida, como se desenhasse seu próprio percurso. (DINIZ, 20I2, p. I5)

No ano de 2008, fui convidada a apresentar Entre Rios e Ruas em uma conferência no Museu de Arte da Pampulha, em Belo Horizonte. Naquela ocasião, fiz uma performance em que distribuí copos cilíndricos com água, com informação impressa sobre a extensão dos córregos canalizados e em leito natural em Belo Horizonte, acompanhada pelo áudio de alguns dos córregos submersos da cidade: Córrego Leitão, Córrego da Serra e Córrego do Acaba Mundo. A proposta de que o público bebesse essa informação reflete bem o espírito do projeto, que parte muitas vezes de informações objetivas, quase técnicas, sobre o tema, e propõe uma abordagem poética, plástica.

A despeito de tratar de questões concretas com formas de abordagem razoavelmente objetivas - fazendo uso de mapas, dados, ações in loco, captação de sons -, a artista não escolhe o caráter documental ou ativista como estratégia principal diante de suas preocupações sociais, urbanísticas e ecológicas, preferindo explorar mormente nossa percepção do real, agindo portanto no campo da subjetividade, nas relações que os indivíduos travam com seus contextos. Sua escolha é, portanto, a de atuar no campo da percepção desse real. (DINIZ, 20I2, p. I8) 


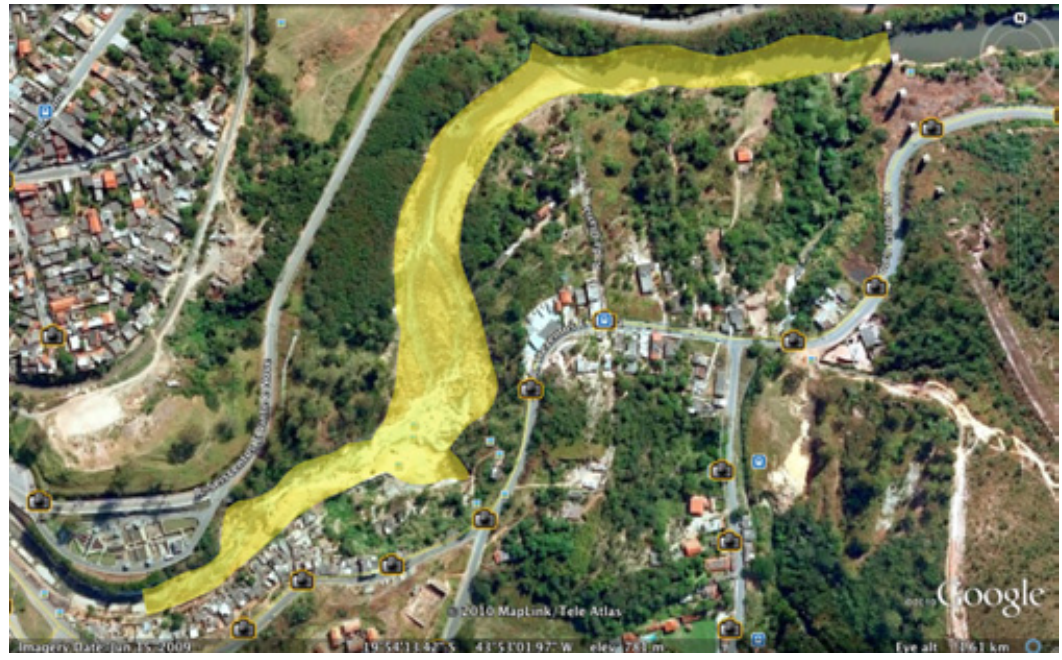

ISABELA PRADO

Jóia. Broche em ouro, $9.5 \mathrm{~cm}, 2010$ (Imagem: Antônio Valadares) 
Em 2012, o projeto Entre Rios e Ruas foi apresentado em exposições em Brasília (Funarte-DF, Prêmio Funarte de Arte Contemporânea 20II) e Belo Horizonte (SESCPalladium). Além do vídeo Mapa Mofo, cabe mencionar três dos trabalhos presentes nessas exposições.

A instalação Repaisagem utiliza mantas magnéticas que correspondem a todos os trechos de córregos em leito natural no município de Belo Horizonte e sugere a participação do espectador, criando novos desenhos, novas paisagens. Assim, o trabalho é definido mediante a participação do outro, que é quem efetivamente o constrói, o transforma. Um desenho sempre

Os trabalhos articulam de forma sutil o contraste entre local e global, entre específico e geral, entre o real e sua representação em formação, contínuo, cujo fim é menos che- abstrata em escala gar a uma imagem, senão emular a própria ideia de passagem e de contínua renovação, tão fundamental às reduzida águas, aos rios, aos mares. A instalação contém ainda um elemento de áudio, que corresponde ao som desses mesmos córregos, mas nesse caso em trechos canalizados, que correm sob as ruas da área central da cidade. Como define Diniz (20I2):

Nessa [instalação], a experiência - vivenciada pelo projeto urbanístico da capital mineira - de reconstruir a paisagem hidrográfica é transformada poeticamente. [...] Repaisagem explora o caráter participativo de obras anteriores de Isabela Prado - como Wind Catcher (2007), Estrangeiro (2006) ou Entre (2006) - numa chave que metaforicamente restaura a potência criativa do indivíduo diante de um mundo e uma sociedade que se fazem passar por dados a priori. (DINIZ, 20I2, p. I7)

Por sua vez, Jóia é um broche feito em ouro e explora a relação entre corpo, espaço e a escala. O desenho dessa joia, de $9,5 \mathrm{~cm}$ de comprimento, replica em escala I:I0.000 o traçado dos últimos 950m de leito natural do Ribeirão Arrudas dentro dos limites do município de Belo Horizonte. De acordo com Jesus (2012):

Carregar a Jóia é o mesmo que carregar o que ainda resta. Fixá-la próxima ao corpo, carregá-la como adereço é o mesmo que carregar um pequeno fragmento de tempo e espaço que remetem de uma só vez para a ausência de uma paisagem e para o jogo da escala. (JESUS, 20I2, p. 22) 
A performance Lição: nessa rua tem um rio consiste em uma sequência de aulas de violino na rua, em que o professor tenta me ensinar a execução da melodia de domínio público "Se esta rua fosse minha”. Como eu nunca tive qualquer contato prévio com o instrumento, tenho grande dificuldade inicial para aprender a "lição". As aulas ocorrem sempre em ruas sob as quais correm trechos dos córregos da cidade. O trabalho é visto como uma metáfora para a dificuldade em estabelecer uma nova relação e uma nova consciência da cidade acerca do ambiente. "Repetitivamente, a artista encena um percurso que não se conclui, próprio à aprendizagem, assim como aos rios" (DINIZ, 20I2, p. I6).

Entre Rios e Ruas quer tornar novamente visíveis os rios que correm sob a cidade, que estão vivos, que se alteram com as estações do ano, na cheia, na seca. E ao explicitar o traçado desses córregos na malha urbana, repensar nossa relação com o que está à nossa volta.

A ocupação do espaço urbano e sua relação com o meio ambiente é uma questão que perpassa todos os trabalhos. Tendo em comum o tema da paisagem e suas infinitas possibilidades de reconfiguração, os trabalhos articulam de forma sutil o contraste entre local e global, entre específico e geral, entre o real e sua representação abstrata em escala reduzida. Busca-se, assim, por meio da metáfora, da participação do espectador e da experiência espacial, uma proposta de recriação da cidade, ativada pela arte e sua força de invenção.

\section{Referências}

DINIZ, C. Rios, ruas, visibilidades. In: ENTRE RIOS E RUAS. Brasília: FUNARTE, 20I2. (Catálogo de exposição).

JESUS, E. Cartografias quase invisíveis. In: GÓMEZ, J. C. (Org.). Isabela Prado: entre rios e ruas. Belo Horizonte: SESC Minas, 2012. 